Fanum

Sociológico

\section{Forum Sociológico}

Série II

$22 \mid 2012$

Saúde e multiculturalidade

\title{
Das competências críticas dos médicos: ilustrações oriundas da medicina paliativa
}

\section{Alexandre Cotovio Martins}

\section{(2) OpenEdition}

Journals

Edição electrónica

URL: https://journals.openedition.org/sociologico/614

DOI: 10.4000/sociologico.614

ISSN: 2182-7427

Editora

CICS.NOVA - Centro Interdisciplinar de Ciências Sociais da Universidade Nova de Lisboa

Refêrencia eletrónica

Alexandre Cotovio Martins, «Das competências críticas dos médicos: ilustrações oriundas da medicina paliativa», Forum Sociológico [Online], 22 | 2012, posto online no dia 26 fevereiro 2013, consultado o 30 março 2022. URL: http://journals.openedition.org/sociologico/614 ; DOI: https:// doi.org/10.4000/sociologico.614

Este documento foi criado de forma automática no dia 30 março 2022.

(C) CICS.NOVA 


\title{
Das competências críticas dos médicos: ilustrações oriundas da medicina paliativa
}

\author{
Alexandre Cotovio Martins
}

«Os médicos e todas as equipas na era moderna não estão muito habituados a lidar [com] a morte.

Nós temos que ter sucesso em tudo. Nós temos que vencer tudo. Nós temos que tratar tudo. Curar tudo. Nas nossas faculdades ninguém nos falava que o doente não ia curar-se e que ia morrer.» Excerto de entrevista (médica de cuidados paliativos)

\section{Apresentação}

1 Este artigo apresenta alguns resultados parciais e oriundos de um processo de investigação conducente a doutoramento, o qual visou estudar o trabalho dos médicos através do quadro teórico usualmente designado sob a expressão genérica de sociologia pragmática. O texto orienta-se, mais especificamente, para o estudo sociológico da crítica realizada pelos atores sociais, a que esta abordagem geralmente se dedica.

2 Nesta ótica, procura-se, em última instância, ilustrar a forma como os médicos demonstram as suas competências críticas no quadro de uma atividade de denúncia, que é igualmente uma atividade de construção de um coletivo no seio da medicina portuguesa. De um ponto de vista mais imediato, o escrito debruça-se sobre os processos pelos quais os médicos dos cuidados paliativos executam uma explicitação pública do seu sentido moral ordinário no trabalho de cuidados, consubstanciada na passagem a uma modalidade de ação crítica, de denúncia, a qual é dirigida àquilo que consideram ser os «excessos» de uma medicina de cariz tecnológico, consolidada numa ação em regime de plano num mundo industrial ${ }^{1}$ (Cf. Boltanski e Thévenot, 1991; 
Martins, 2010). Este trabalho crítico desenvolvido pelos médicos é apreendido sob uma dupla perspetiva: i) enquanto trabalho de revelação pública do sentido moral destes médicos, de translação desse sentido moral para um regime de ação mais geral, sentido moral que é primariamente desenvolvido no seio da sua atividade quotidiana; e ii) enquanto modo de enquadramento e definição de um coletivo crítico no seio da medicina portuguesa.

3 Os dados aqui expostos foram extraídos de um corpus documental diversificado, do qual se salientam as seguintes fontes: obras diversas, escritas por médicos, sobre o trabalho médico, mormente em contexto de paliação; várias dissertações de mestrado em cuidados paliativos, defendidas por profissionais de medicina nas Faculdades de Medicina portuguesas; observação direta nos hospitais; e um conjunto de dezoito entrevistas em profundidade realizadas a médicos que trabalham em cuidados paliativos em Portugal (num universo de vinte e oito médicos a exercerem esta função no país ${ }^{2}$, segundo dados da Associação Portuguesa de Cuidados Paliativos).

\section{Para uma sociologia dos cuidados médicos paliativos: uma abordagem pragmática}

\section{Regimes de ação: entre o próximo e o público}

O conceito fundamental a partir do qual procuramos sustentar a construção de uma abordagem sociológica sobre o nosso objeto empírico é o de ação. Mais precisamente, utilizamos um conceito de ação na aceção desenvolvida no quadro da sociologia pragmática (Thévenot, 2006). Devemos, assim, entender a ação a partir das modalidades pelas quais a(s) pessoa(s) se envolve( $m$ ) na ação e também das formas como, neste envolvimento, se coordena $(m)$ com os outros e consigo própria(s). A estas diferentes modalidades de envolvimento chamaremos de regimes de envolvimento na ação. Cada diferente regime de envolvimento na ação é convocado pela pessoa, em situação, justamente em função do juízo realizado por si acerca dessa mesma situação. Tal juízo, interpretativo ou outro, implica a seleção e organização de elementos da situação por parte da pessoa, que o faz segundo diferentes figurações da ação, coordenando (de si para si, de si para os outros e de si para o mundo) a sua conduta em consequência deste processo. Deste modo, a pessoa efetiva aquilo a que se pode chamar de uma ação que convém, no sentido preciso em que resulta de uma avaliação ou de um juízo situado.

Esta conveniência pode distribuir-se por diferentes domínios e níveis, passíveis de classificação analítica. Podemos distinguir diferentes regimes de envolvimento na ação em função de um eixo analítico que vai do particular ao geral, das conveniências locais e familiares às convenções coletivas próprias do espaço público. Deste modo, uma classificação dos regimes de envolvimento na ação pode dividi-los em: i) regime de ação familiar, centrado numa ação em registo de proximidade, localizada, cumprida a partir de um processo com uma espessura temporal específica e em que a pessoa age a partir de uma longa familiarização dinâmica com as pessoas e objetos envolvidos na sua ação. É um regime de acomodação mútua da pessoa e do seu ambiente direto. O grau de generalização aqui é mínimo, ao ponto de mesmo a língua nem sempre trazer aqui pregnância significativa (por demasiado geral: o copo que eu seguro pode, neste regime, deter para mim um sentido que a expressão genérica "copo" não permite expressar) - o que, aliás, constitui, noutra ótica, problema metodológico interessante; 
ii) um regime de ação em plano, orientado de forma mais "estratégica" e em que o envolvimento na ação é funcional por referência a determinados propósitos; iii) um regime de ação público, no qual a ação é orientada por convenções de grande alcance cognitivo e moral socialmente difundidas e que visam qualificar os seres e ações envolvidos num determinado processo de ação ou numa situação determinada. 0 grau de generalização aqui é máximo e os constrangimentos impostos à ação pelas diferentes ordens convencionais que especificam a ação são muito fortes.

6 Procedendo inversamente, podemos procurar averiguar o grau de penetração dos regimes menos gerais e mais localizados pelas convenções típicas do regime público. Antes de mais importa, contudo, ter presente que o regime público é todo ele percorrido, nas sociedades modernas, por diferentes ordens de convenções, que configuram outros tantos quadros de referência cognitiva e moral e permitem a qualificação dos seres (humanos ou não humanos) e ações. Tais ordens de convenções podem nomear-se de Cités (Boltanski \& Thévenot, 1991), no sentido em que são grandes contruções convencionais que permitem a apreciação e a modulação da formação do laço social e político e especificam, cada uma delas, uma expressão particular do bem comum da comunidade. Tais formas de bem comum organizam-se a partir de diferentes princípios superiores comuns. Assim, a título de exemplo, uma ordem convencional industrial tem como princípio superior comum a eficácia, da mesma forma que uma ordem convencional mercantil a concorrência, e assim sucessivamente. Existe toda uma axiomática das Cités (cujo número é limitado) que não importa desenvolver aqui.

7 Mas averiguávamos do grau de penetração dos regimes de envolvimento na acção mais particulares pelos regimes mais gerais, designadamente através das respetivas gramáticas convencionais socialmente disponíveis. O regime público é, todo ele, dissemos, cursado por estas Cités. Por outro lado, elas consolidam-se historicamente em diferentes mundos ou naturezas. Tais mundos ou naturezas são conjuntos organizados de dispositivos que, inspirados naquelas diferentes ordens convencionais, são utilizados pelas pessoas para avaliarem a sua grandeza específica e a dos outros (isto é, estamos no domínio por excelência do reconhecimento, mas também da legitimidade). São repertórios de objetos (materiais e imateriais) e pessoas, qualificados ou qualificáveis, por exemplo no seio de uma disputa enquadrada por uma determinada ordem de convenções. Pois bem, fora das situações públicas, nas quais existe um forte imperativo de escrutínio das qualificações das pessoas e objetos, estes mundos consolidados são o ambiente normal da vida quotidiana das pessoas, quando agem num regime de plano.

8 Assim, a título ilustrativo, num mundo industrial, a ação "normal", isto é, em plano, de um médico é levada a cabo tendo em vista um princípio de eficácia e produtividade nos seus atos, num ambiente espacial e temporal, todo ele (ou maioritariamente, para ser rigoroso) constituído no mesmo sentido: são as máquinas de diagnóstico e terapêutica, como os corredores descoloridos ou uma hierarquia bem oleada em torno da competência técnica do médico, assim como uma conceção e organização homogéneas, progressivas e lineares do tempo.

9 No regime de plano, todavia, as exigências axiomáticas das ordens de convenções não são tão fortes como no regime público (porque há menores exigências de generalidade) e, por outro lado, a ação dá-se em ambientes em que os dispositivos (materiais ou imateriais) existentes e (re)conhecidos pelas pessoas já incorporam, também, os compromissos entre diferentes ordens convencionais realizados anteriormente, quer na esfera pública, quer na ação em plano. Um exemplo claro disto é a existência de um 
compromisso cívico-industrial (portanto, entre uma Cité e um mundo industrial e uma Cité e um mundo cívico) no domínio da saúde, paradigmaticamente consolidado na área da saúde pública, em que as exigências dos coletivos sociais se harmonizam, sob a égide do Estado, com as exigências de eficácia no tratamento da doença característica de uma medicina centrada nas ciências fundamentais. Este compromisso é apreensível em objetos e ações diversas.

10 Finalmente, o regime familiar, em função do seu particularismo, é escassamente ou mesmo nada penetrado pelas diferentes ordens convencionais ou pelos seus dispositivos consolidados. Podendo mesmo tratar-se dos mesmos objetos, a dinâmica do envolvimento face aos mesmos é outra, particularista, localizada, dir-se-ia mesmo personalizada (no sentido forte do termo, não no sentido quase clientelar hoje tanto em voga). O regime familiar é, pois, um regime de proximidade, de personalização, de hospitalidade, também, uma vez que o bem nele envolvido é o conforto, o bem-estar.

\section{Experiência da singularidade e ativação da denúncia: médicos críticos da medicina (industrial)}

\section{A defesa da medicina orientada para a singularidade}

11 Pudemos constatar, em estudo anterior (Martins, 2010), que os médicos de cuidados paliativos em Portugal Continental desenvolvem, presentemente, um esforço de afirmação da diferença da medicina paliativa face a outras modalidades de medicina, com especial relevo para a medicina orientada para o combate à doença e a promoção da cura, que designámos, então, como medicina constituída no seio de um compromisso cívico-industrial.

Os argumentos dos médicos que trabalham em medicina paliativa para distinguirem a mesma de uma medicina curativa mais centrada na eficácia do ato médico e, frequentemente, consolidada no seio de um compromisso cívico-industrial, são argumentos que procuram recuperar os aspetos que classificam de humanos da relação entre médicos - e restante equipa de saúde - e os doentes. Esta é uma dimensão central do discurso destes médicos e da sua atuação profissional, nos termos daquilo que dela explicitam quando solicitados a fazê-lo. Esta nativamente designada dimensão humana da ação médica nos cuidados paliativos centra-se muito fortemente naquilo que os médicos consideram ser uma especial atenção e solicitude médica face ao doente, atenção e solicitude que, entendem, devem expandir-se muito para além daquilo que são os aspetos mais fortemente objetivos e eficazes, do ponto de vista diagnóstico e terapêutico, de uma ação médica curativa e orientada para a eficácia do ato médico na luta contra a doença. Tal operação de "extensão" do ato médico inclui no mesmo aquilo que podemos denominar como um regime de ação familiar ou de ação em proximidade (cf. Thévenot, 2006), ativado por estes médicos no sentido de promover, na sua ótica, o conforto e o bem-estar do doente terminal e sua família, num quadro de estreita e próxima atenção ao doente e, assim, minorar o mais possível o seu sofrimento.

observar o doente, interagir com ele de forma a conseguir interpretar com segurança aquela que é a dimensão do seu sofrimento e os domínios em que este se repercute tem necessariamente, segundo estes médicos, de implicar uma abordagem clínica fortemente diferenciada daquela que é típica de um trabalho numa ordem convencional altamente racionalizada e protocolarizada como a de uma medicina "convencional". 
Nestes termos, a clínica dos cuidados paliativos é encarada pelos profissionais como uma clínica orientada para abordagens qualitativas, narrativas, fenomenológicas. Aqui, o médico é muitas vezes visto pelos proponentes de uma abordagem de cuidados paliativos como um parceiro do doente no processo de confeção, de construção de sentido sobre esta experiência a partir de todo o percurso da sua vida que este tendencialmente irá considerar.

\section{A centralidade das controvérsias no enquadramento coletivo da ação}

14 Este quadro de representação e ação, que caracteriza a medicina paliativa e, afinal, o sentido moral dos médicos de cuidados paliativos entrevistados, tem vindo a ser trazido à discussão pública, nomeadamente pelos profissionais que trabalham na área. De entre os profissionais de saúde que trabalham em cuidados paliativos, os médicos desempenham um papel preponderante na divulgação dos aspetos mais fundamentais deste mesmo quadro (Resende, 2006). Efetivamente, os médicos têm vindo, ao longo dos últimos quinze anos, a trazer ao espaço público a temática dos cuidados paliativos, no sentido de "a sociedade» se aperceber daquilo que consideram ser as necessidades específicas destes doentes e a especificidade da abordagem de cuidados de final de vida. O trabalho de exposição pública dos cuidados paliativos realizado por estes médicos tende a centrar-se no valor da atenuação do sofrimento por contraposição ao valor, característico de uma medicina industrial, da preservação da vida a todo o custo (cfr. idem).

Ora, procurar analisar sociologicamente o trabalho de tradução pública dos temas e problemas que constituem um coletivo e a forma como as controvérsias geradas no espaço público contribuem para reforçar esse coletivo - no caso, os médicos ligados diretamente à medicina paliativa - implica a compreensão das condições de ação nas sociedades modernas ${ }^{3}$. Para tanto, é adequado trabalhar o contributo de autores que recentemente atualizaram e aperfeiçoaram, se assim podemos dizer, o conceito de ação social sem, no entanto, deixarem cair três aspetos fundamentais dessa mesma ação que já Max Weber tinha, de forma mais sublinhada nuns casos que noutros, vincado.

16 Os aspetos de que falamos são os seguintes: i) o caráter significativo da ação social, aspeto central na sociologia weberiana; ii) a importância da representação da legitimidade da ordem social na qual os indivíduos participam para a sua atividade social e o facto de estes recorrerem a princípios ou «máximas» para justificarem a sua ação; iii) a abertura à análise da pluralidade de formas de ação, coexistentes num mesmo indivíduo, de que Weber se aproximou, designadamente quando explicitou a sua célebre tipologia da ação social.

Um primeiro aspeto axial para a análise das modalidades pelas quais os coletivos se organizam a partir da geração de controvérsias é o caráter significativo da respetiva ação. Como afirma David Snow, a análise dos quadros de ação coletiva e sua importância na estruturação de coletivos implica a interpretação do sentido dado pelos indivíduos neles participantes à sua ação (Snow, 2001). Existe, nesta atividade de enquadramento, que é uma atividade de atribuição e construção social de sentido, uma dimensão retórica, porquanto os participantes num esforço de construção de um coletivo, por exemplo, um público, organizam um trabalho permanente de convocação 
e/ou construção de significados que sejam capazes de produzir efeitos sociais relevantes para o movimento no qual se sentem participantes.

Em segundo lugar, esta atividade, ou este trabalho sobre o sentido, refere-se à representação de ordens legítimas, porquanto os atores sociais, enquanto seres socialmente competentes numa sociedade determinada, organizam a sua ação de construção de coletivos a partir de gramáticas sociais e políticas socialmente disponíveis que justificam o seu ponto de vista e a sua ação. Ou seja, os atores sociais recorrem a princípios de justificação da sua ação e da sua visão sobre um determinado objeto que conferem o caráter de ordem (no sentido de Weber) ao conteúdo significativo das suas relações sociais. Tal implica que o enquadramento público da ação coletiva tem de se conformar amplamente à expressão através de gramáticas (cfr. Boltanski e Thèvenot, 1991) do laço social e político amplamente difundidas socialmente no contexto da modernidade. Este é um trabalho de "subida em generalidade" que fornece um largo alcance cognitivo e moral às reivindicações particulares (mas não necessariamente particularistas) de grupos específicos (Barbot, 2001).

Interessante é notar que esta convocação estratégica de gramáticas justificativas, visando a atribuição de sentido à ação e a legitimação de uma determinada representação ordenada e ordenadora, no quadro da qual essa ação decorre, se organiza frequentemente em torno de controvérsias ou "problemas sociais". Estas controvérsias ou problemas são, por sua vez, estruturantes na definição dos grupos, na medida em que estes tendem a fazer-se, enquanto coletivos com um certo grau de mobilização, em função das tomadas de posição, mais ou menos públicas, que os diferentes intervenientes assumem face a essas controvérsias.

Podemos, por outro lado, encarar estas controvérsias como operações de dramatização e organização retórica, em resumo, de codificação ou recodificação pública do significado produzido ao nível de regimes mais localizados de ação. Este trabalho de codificação é assim, também, um trabalho de produção da crença na legitimidade da ordem (ou ordens) ou na legitimidade da contestação da ordem na qual os seus intervenientes (os médicos) participam ou não e com a qual se identificam ou não.

21 O terceiro aspeto importante a salientar é que, no trabalho de mobilização retórica de gramáticas justificativas, os atores sociais convocam diferentes ordens de legitimação e, portanto, justificação das suas tomadas de posição. Ou seja, o debate não se resume necessariamente à produção discursiva e à mobilização social no quadro de uma mesma ordem justificativa, antes pode decorrer em diferentes ordens. Assim, o trabalho retórico de enquadramento é um trabalho plural, no sentido em que recorre amiúde a diferentes ordenamentos justificativos para realizar processos de configuração e reconfiguração de campos, grupos e situações. $O$ trabalho de transição entre diferentes ordens de convenções (gramáticas) em sucessivas situações, mas também de negociação e compromisso entre elementos convencionais oriundos de diferentes ordens e regimes de ação, apenas pode ser levado a cabo, por sua vez, por atores socialmente competentes e com competências cognitivas e morais particularmente desenvolvidas (Boltanski, 1990). 


\section{Dimensões da crítica (I): morte natural e crítica doméstica ao mundo industrial}

Podemos nesta fase ter presente que muita da crítica ${ }^{4}$ ao estabelecimento da medicina iátrica, em condições de modernidade e construída no seio de uma ordem convencional industrial, tem sido sucessivamente desarmada pelos sucessos daquilo que é uma ação médica altamente racionalizada, tecnicizada e orientada para a eficácia, preventiva ou terapêutica. Não obstante, com o surgimento dos cuidados paliativos, pode observar-se a emergência de um conjunto de críticas e denúncias feitas a esta modalidade de medicina, críticas estas assentes numa ordem convencional não industrial. Tais críticas e denúncias centram-se na questão do sofrimento dos doentes e, especialmente, no sofrimento causado, advoga-se, pela própria medicina. Ora a medicina, enquanto referida a uma ordem industrial ${ }^{5}$ no seio daquilo que podemos designar de um compromisso entre uma ordem industrial e uma ordem cívica, é geralmente criticada por aqueles médicos por tender, entende-se, a apreender as pessoas e, mais particularmente, as pessoas doentes, sob uma modalidade percetiva e avaliativa categorial que é pouco sensível aos particularismos da situação específica de cada um. A crítica dirige-se assim a uma forma de julgamento e correlativo envolvimento na ação que se entende poder depreciar as dimensões subjetivas e sobretudo não objetiváveis do sofrimento dos doentes, que poderão não ser reconhecidas como passíveis de receberem a atenção e o cuidado médico (cfr. Martins, 2010).

Ora, para os médicos críticos entrevistados, o sofrimento dos doentes tende a ser tanto maior quanto, consideram, esta modalidade de medicina se inclina, de certa maneira, a recalcar, ou pelo menos esquecer, a questão da morte e da assistência médica em final de vida. Naquilo que os médicos críticos consideram ser os excessos causados por um certo fervor na busca de meios sempre mais eficazes de luta contra a doença, perde-se até certo ponto, argumentam, a especificidade do ato médico dirigido a doentes que já não podem ser curados. Um médico não deve, de acordo com os médicos auscultados, ser apenas alguém que utiliza atos eficazes no combate à doença; tem de ser sempre, antes de qualquer outra coisa, alguém capaz de cuidar e de aliviar o sofrimento dos seus doentes:

O médico não pode só pensar resolver aquele problema que o doente trouxe, pôr tudo para trás e olhar só para ali. Não querer saber do resto. É muito bonito, as pessoas irem para os congressos dizer que veem o doente como um todo, etc., e depois, na prática, não fazem nada. Essa prática tem que ser alterada. Para se ser verdadeiramente médico, não se pode ser curador de doenças. Tem que se ser tratador de pessoas. Para se ser verdadeiramente médico, tem que se saber tratar de pessoas e as pessoas são um todo. São um todo, com o seu sofrimento. Com os seus problemas físico-sociais [excerto de entrevista a médico de cuidados paliativos].

Este é o locus visado pela crítica: o não reconhecimento das dimensões extrínsecas a uma medicina curativa. Mas, identificado o mesmo, que podemos dizer quanto aos argumentos justificativos da própria crítica convocadas por estes atores? Quanto a este ponto, constatamos que uma característica fundamental da crítica dirigida pelos médicos dos cuidados paliativos à medicina industrial é a utilização de uma argumentação assente numa natureza doméstica ${ }^{6}$. Com efeito, o discurso dos médicos defensores de uma abordagem de cuidados paliativos incorpora uma interpretação do final de vida largamente ancorada numa representação naturalizada da morte. Ora, segundo Boltanski e Thévenot, um dos principais móbeis da crítica doméstica ao mundo 
industrial tem que ver com a recusa, ao menos parcial, da aplicação de técnicas produtivistas que tentam controlar certos ritmos e formas naturais, integrando-os num esquema produtivo que lhes retira, argumenta-se, qualidade. Esta crítica centra-se frequentemente na argumentação construída contra uma visão, denunciada como tecnicista, que procura ser eficaz face a um determinado objetivo, quando o seu principal efeito é, de acordo com esta interpretação doméstica, a rutura de certos equilíbrios naturais e a degradação da qualidade daquilo que provém da natureza doméstica.

Este quadro normativo é particularmente saliente nas afirmações produzidas por uma médica de cuidados paliativos numa sua publicação acerca desta temática (Neto et al., 2004):

A intensidade da luta pela busca da cura de muitas doenças e a sofisticação dos meios associados a essa luta levaram, de algum modo, a uma cultura de "negação da morte", de "triunfalismo heróico sobre a mesma", de "ilusão de pleno controlo sobre a doença", relegando para segundo plano as intervenções na saúde que, longe de garantir a cura, garantissem e promovessem um final de vida condigno. A morte passou a ser negada e encarada como "derrota" por muitos profissionais de saúde, como falhanço e frustração, e o treino dos profissionais sofreu, de algum modo, uma desumanização, com menor enfoque nas questões em torno da "não-cura"'.

\section{Dimensões da crítica (II): a crítica à formação médica dominante}

26 As considerações precedentes permitem-nos dar conta da existência de uma crítica realizada por médicos defensores dos cuidados paliativos a uma medicina designada de "triunfalista" e encarada como excessivamente confiante nos seus próprios poderes e progressos, "desumanizada" (cfr. Neto et al., op.cit.). Esta crítica radica na denúncia daquilo que estes médicos dizem ser o sofrimento dos doentes terminais a cargo de colegas seus formados e treinados numa clínica orientada para a doença.

Os médicos críticos denunciam o sofrimento nos termos observados por Boltanski (Boltanski, 2007), procurando um perseguidor, alguém que induza ou produza o sofrimento que se denuncia. Analisando o discurso destes médicos críticos a partir desta noção, verifica-se que a figura do perseguidor é incarnada pelos seus colegas mais rotinizados numa medicina curativa ou preventiva, orientada para a luta contra a doença, que entendem possuir uma formação saída das faculdades de medicina que julgam ser demasiado "técnica" e demasiado pouco "humana".

Por outro lado, esta crítica chega, muitas vezes, a fundar-se, como também é observado por Boltanski nas suas análises sobre a exposição pública do sofrimento, numa teoria da dominação (cfr. idem). É o "modelo biomédico", a "cultura dominante" ou a "modernidade desumanizante" que configuram por vezes, no entender destes médicos, dispositivos sociais, económicos, políticos e sobretudo médicos que redundam no sofrimento dos dependentes e na ignorância ativa dos aspetos mais subjetivos e singulares da pessoa doente. Como se vê, trata-se aqui da denúncia daquilo que se ajuíza ser uma espécie de sistema de dominação que é, no fundo, a medicina organizada num mundo cívico-industrial, captada a partir de uma ótica crítica.

Assim, muito embora a discussão em torno da natureza da morte e da concomitante especificidade dos cuidados a doentes terminais seja um dos motivos geradores de 
controvérsia no domínio da medicina paliativa, a crítica doméstica ao mundo industrial na medicina dirige-se, sob este quadro genérico, a outras dimensões desta atividade.

Um aspeto forte da denúncia é o referido problema da formação dos médicos de acordo com uma ordem convencional industrial. $\mathrm{Na}$ verdade, os médicos - e outros profissionais - ligados aos cuidados paliativos tendem, de acordo quer com os documentos analisados ${ }^{8}$, quer com as entrevistas, a criticar a formação médica que classificam de "tradicional" ou "clássica", isto é, aquela que hoje em dia entendem ser regularmente oferecida nas faculdades de Medicina. Segundo estes médicos, a formação dominante nas faculdades e institutos médicos é uma formação fortemente orientada para a cura e a eficácia na prevenção e no combate à doença. Esta formação, dirigida sobretudo a doentes sem episódios de perda maior e irreversível de autonomia e independência, não prepara, argumentam, os médicos para o trabalho com doentes crónicos ou terminais.

Eu penso que [estes problemas] resulta[m] da formação das pessoas. Da história da medicina recente, com a história do desenvolvimento tecnológico, sobretudo. $\mathrm{E}$ cometeu uma evolução grande, mas não se aplica a toda a gente, em todas as fases de doenças. Então, aquilo que as pessoas são ensinadas nas faculdades é a curar, curar a vida, sobretudo em relação a esses aspetos tecnológicos, e quando estes deixam de ser úteis, então passa-se a bola para outro sector, digamos assim, quando existe, em que se pensa não só no curar, até porque já não se pensa no curar, porque já não é possível, mas no cuidar [entrevista a médico de cuidados paliativos].

Os profissionais ligados aos cuidados paliativos consideram o problema da formação médica atual como um dos principais obstáculos ao desenvolvimento de cuidados "de qualidade" aos doentes terminais, quer porque - afirmam - os médicos não saem das suas formações com competências ou sequer sensibilizados para este problema, quer ainda porque, em função desta sua alegada falta de preparação, as soluções encontradas pecam frequentemente por serem relativamente aleatórias, dependentes da vontade e das opções de cada médico e das possibilidades concretas de prestação de cuidados relativamente específicos aos doentes terminais num ambiente que geralmente não foi concebido para o efeito, que é o hospital.

\section{Dimensões da crítica (III): a crítica às formas de engrandecimento médico num mundo industrial}

A acima referenciada sistematização crítica tende a alargar-se para lá dos aspetos da mera formação médica, indo igualmente incidir na hierarquização das especialidades médicas e nos respetivos critérios meritocráticos (típicos de uma ordem convencional industrial). Numa medicina organizada no seio de um mundo industrial, as especialidades mais valorizadas são aquelas que apresentam mais resultados, isto é, que são capazes de curar, de otimizar, racionalizar a prática médica e que se baseiam fundamentalmente na competência técnica dos profissionais respetivos, ela própria assente num domínio clínico das técnicas médicas assentes nas ditas ciências fundamentais.

Na representação crítica partilhada pelos médicos da medicina paliativa e dirigida a este tipo de perspetiva e de ação, a associação entre saber e poder médico nas organizações de saúde, nomeadamente hospitalares, onde se concentra o trabalho da maioria das especialidades médicas, ganha o seu sentido pleno; num mundo médico em 
que aquilo que se valoriza é a competência técnica e a sua eficácia, o saber especializado tem todas as condições para afirmar a legitimidade do seu poder organizacional, entende-se. Assim, surgem nas entrevistas mas também em livros e publicações médicas, bem como teses de mestrado de médicos, críticas muito próximas das realizadas por cientistas sociais e filósofos sociais, como a denúncia ao poder biomédico, com fortes raízes foucaultianas.

Nós vemos muito nos hospitais o modelo biomédico, em que o médico dispõe um pouco, de acordo com conhecimentos técnicos, dispõe um pouco do doente e decide o que é que o doente deve fazer e é nesse contexto que às vezes há necessidade de pensarmos nas outras dimensões da pessoa e se calhar abordarmos este sentido [entrevista a médica de cuidados paliativos].

No entanto, se estes médicos exercem estas duras críticas sobre os colegas e dispositivos mais próprios de uma ordem cívico-industrial, fazem-no, não para negarem a importância da ação médica eficaz na luta contra a doença, mas para reivindicarem um certo pluralismo da ação médica, no caso organizado numa lógica de cuidados. Assim, não se denuncia a medicina eficaz, sem mais, mas a medicina eficaz enquanto modelo único ou pelo menos dominante na profissão no período moderno. Por conseguinte, esta é sobretudo a denúncia do que se crê ser a tendência, na "medicina convencional", para a menorização de toda a atividade médica não eficaz do ponto de vista terapêutico e afastada do núcleo duro das técnicas e tecnologias altamente dependentes dos desenvolvimentos nas ciências fundamentais.

A associação entre o saber especializado médico e a sua posição profissional, objetivada nas carreiras médicas hospitalares, é, na mesma linha de argumentação, denunciada como uma espécie de obstáculo à implementação de uma filosofia e uma ação de cuidados efetivos a doentes terminais. Considera-se, pois, que existe uma estrita definição das carreiras, baseada sobretudo nos aspetos técnicos de um mundo industrial, e que a mesma é correlativa de uma simbólica estatutária e de uma grande rigidez identitária dos seus colegas. Este «sistema» de ação tem efeitos deletérios sobre os doentes em situação de forte dependência, nesta sociologia espontânea dos médicos.

\section{Palavras finais}

O texto aqui desenvolvido visou trazer à discussão dados de natureza sociológica - bem como a respetiva interpretação teórica -, os quais demonstram, antes de qualquer outra coisa, a existência de muito claras competências críticas dos médicos, desenvolvidas a propósito do seu trabalho no contexto dos cuidados paliativos. Estas competências críticas são ativadas por estes profissionais no sentido de definirem situações mas também posições morais perante situações, o que significa que organizam uma forma específica de realismo médico, se assim lhe podemos chamar. Com efeito, a redução crítica da medicina "convencional" realizada no e pelo esforço crítico destes profissionais é concomitante de uma justificação da medicina paliativa assente numa natureza doméstica. Assim, estes médicos enunciam um projeto crítico de mudança de certos aspetos da atividade médica, a partir do qual pretendem engrandecer publicamente as figuras da proximidade (finalidade para a qual parece especialmente azada a justificação doméstica9 ${ }^{9}$. Ora, tal projeto traz consigo conceções cognitivas e éticas do que ée do que deve ser a medicina. 
Por outro lado, gostaríamos de focar um aspecto menos diretamente trabalhado no texto, mas o qual lhe subjaz em permanência: o que se refere à forte identificação dos médicos entrevistados com estas operações críticas e as conceções de medicina que lhes são solidárias. Deste ponto de vista, o processo de codificação e translação crítica do sentido moral comum dos médicos dos cuidados paliativos para o domínio público é também um processo de construção de um coletivo no âmbito dos profissionais de medicina em Portugal. As exigências de reconhecimento postas em jogo na argumentação crítica podem assim, talvez, ser encaradas, não apenas como demandas de reconhecimento da situação, dita específica, dos doentes terminais, mas também como demandas de reconhecimento de uma forma de fazer medicina e daqueles que nela se reveem.

\section{BIBLIOGRAFIA}

BARBOT, J. (2001), «S'engager dans le monde biomédical - Diversité et front commun des associations», in D. Cefaï e D. Trom (orgs.), Les formes de l'action collective - mobilisations dans des arènes publiques, Paris, Éditions de l'École des Hautes Études en Sciences Sociales.

BENFORD, R. e S. Hunt (2001), "Cadrages en conflit - mouvements sociaux et problèmes sociaux", in D. Cefaï e D. Trom, Danny (orgs.), Les formes de l'action collective - mobilisations dans des arènes publiques, Paris, Éditions de l'École des Hautes Études en Sciences Sociales.

BERNARDO, A. M. C. S. (2005), Avaliação de Sintomas em Cuidados Paliativos, Tese de Mestrado em Cuidados Paliativos, Faculdade de Medicina - Universidade de Lisboa, Lisboa.

BOLTANSKI, L. (1990), L'amour et la justice comme compétences. Trois essais de sociologie de l'action, Paris, Éditions Métailié.

BOLTANSKI, L. (2007), La souffrance à distance - morale humanitaire, médias et politique, Paris, Gallimard.

BOLTANSKI, L. e L. Thévenot (1991), De la justification. Les économies de la grandeur, Paris, Gallimard.

FREIDSON, E. (1970), Professional dominance: the social structure of medical care, Nova Iorque, Atherton Press.

FREIDSON, E. (1988), Professional powers - A study of the institutionalization of formal knowledge, Chicago, The University of Chicago Press.

FREIDSON, E. (1994), Professionalism reborn: Theory, prophecy and polity, Chicago, The University of Chicago Press.

FREIDSON, E. e J. Lorber (Éds.) (1972), Medical men and their work, Chicago, Aldine-Atherton.

MARTINS, A. (2010), A medicina paliativa como medicina de proximidade. Suspensão dos julgamentos gerais e acção médica em regime de familiaridade, Tese de Doutoramento em Sociologia, Faculdade de Ciências Sociais e Humanas - Universidade Nova de Lisboa, Lisboa.

NETO, I. G. et al. (2004), A Dignidade e o Sentido da Vida. Uma reflexão sobre a Nossa Existência, Lisboa, Pergaminho. 
RESENDE, J. (2006), «A morte saiu à rua»: aproximações à morte entre o sofrimento e a preservação da vida. II Congresso Internacional de Saúde, Cultura e Sociedade, Tavira, Setembro.

SNOW, D. (2001), “Analyse de cadres et mouvements sociaux”, in D. Cefaï e D. Trom (orgs.), Les formes de l'action collective - mobilisations dans des arènes publiques, Paris, Éditions de l'École des Hautes Études en Sciences Sociales.

THÉVENOT, L. (2006), L'action au pluriel - sociologie des régimes d'engagement, Paris, Éditions La Découverte.

THÉVENOT, L. (2009), "Postscript to the special issue", in Social Studies of Science, 39: 793-813.

\section{NOTAS}

1. Não se trata, aqui, de uma composição entre regimes pragmáticos, na exata medida em que a definição de envolvimento em plano de Thévenot implica que se considere que a ação em plano requer um ambiente estabilizado, o qual é coerente com um regime pragmático de justificação industrial. Assim, trata-se aqui da ação em plano apoiada em objetos qualificados no quadro de uma «metafísica social» estabelecida no quadro da Cité industrial. Sobre este assunto, cfr Thévenot, L. (2006), L'action au pluriel - sociologie des régimes d'engagement, Paris, Éditions La Découverte, p. 124.

2. Reportamo-nos a dados de 2008.

3. Em termos contemporâneos, as sociedades da modernidade liberal alargada, para retomar a expressão de Peter Wagner.

4. Sobre a denúncia e a crítica como objetos da sociologia, ver Boltanski, L. (1990), L'amour et la justice comme compétences. Trois essais de sociologie de l'action, Paris, Éditions Métailié, passim.

5. Neste texto, por razões de economia de espaço, centrar-nos-emos na análise da crítica aos aspetos industriais da medicina.

6. Para uma explicitação deste conceito, cfr. Boltanski, L. e Thévenot, L. (1991), De la justification. Les économies de la grandeur, Paris, Éditions Gallimard, passim.

7. Saliente-se que não entende a generalidade destes médicos serem os avanços científicos e tecnológicos na medicina de rejeitar; a sua crítica dirige-se àquilo que consideram ser os défices aí produzidos, designadamente junto dos doentes terminais.

8. Nomeadamente, teses de mestrado em cuidados paliativos, livros e artigos e entrevistas a jornais.

9. Como aliás reconhece Thévenot. Cfr. Thévenot, L. (2006), L'action au pluriel - sociologie des régimes d'engagement, Paris, Éditions La Découverte.

\section{RESUMOS}

Discutem-se neste artigo tomadas de posição de médicos de cuidados paliativos a exercerem medicina em hospitais de Portugal Continental, a propósito da sua defesa pública deste tipo de cuidados. O foco da análise centra-se no processo de tradução pública do sentido moral que constroem na sua atividade profissional quotidiana e na exemplificação, concomitante, das suas competências críticas, enquanto atores socialmente competentes. 
This article discusses the stances held in public by palliative care physicians which practice their professional activity in hospitals of mainland Portugal, in relation to their defense of this type of care. The analysis is focused upon the process of public translation of the moral sense which these doctors build in their daily professional activity and in the simultaneous exemplification of their critical competences, which they possess as socially competent actors.

\section{ÍNDICE}

Keywords: palliative medicine, critique, public

Palavras-chave: medicina paliativa, crítica, público

\section{AUTOR}

\section{ALEXANDRE COTOVIO MARTINS}

Escola Superior de Educação de Portalegre - CesNova-UNL - Centro Interdisciplinar de Investigação e Inovação do Instituto Politécnico de Portalegre (alxmiguelc@gmail.com) 